\title{
Analysis of sustainable development of rural areas in Russia: results, challenges and solutions
}

\author{
Natalia Ovchinnikova, ${ }^{1, *}$ \\ ${ }^{1}$ Don State Technical University, pl. Gagarina, 1, Rostov-on-Don, 344003, Russia
}

\begin{abstract}
This article discusses the concept of sustainable development in general and in relation to rural areas. It describes the multitasking functionality of rural areas. Main issues of all spheres of rural life are analyzed, and the necessity of practical implementation of state programs for sustainable rural development is argued. The results of development programs, the challenges of their implementation are considered, and ways of solving them are proposed in order to identify indicators of the current state and progress of sustainable development in our country, to compare them with other countries in order to better understand where we are, what we have achieved and where additional efforts are needed. There is still a lot of work to be done to achieve our goals, as not all the indicators analyzed are positive.
\end{abstract}

\section{Introduction}

In today's environment, the development of rural areas is an important area that contributes to sustainable economic development in Russia. Developed rural areas are a guarantee of stable life in our country. For this purpose, it is necessary to improve the quality of life of the rural population by reducing differences between cities and villages in the social and labor system.

\section{Materials and methods.}

The Land Fund of the Russian Federation covers 17.1 million square kilometers. Almost two thirds of this territory is accounted for rural areas. About $25 \%$ of our population currently lives in rural areas. From a scientific point of view, rural areas are usually understood as inhabited areas outside large cities with their environmental conditions and resources, rural population and results of people work, i.e. various elements of material culture and main production assets in the area.

In recent decades, the theme of rural development in our country has been raised quite frequently. It is particularly relevant these days. This is due to unfavorable demographic changes, i.e. constant shrinking of population of rural settlements. According to the Statistics Service report issued in 2017, in the future the process of decreasing of rural population will be accelerating and by 2036 the number of rural residents will decrease by another 4.6 million (to 33 million) [1-2].

\footnotetext{
${ }^{*}$ Correcting author: donong160875@yandex.ru
} 
In addition to disrupting the village's ability to perform its multiple functions, this problem also restricts the ability to achieve the goals of national demographic development.

The standard of living in villages is declining. All life aspects of the rural population are deteriorating due to unemployment, poorly developed transport and road systems, decentralized gas and water supply in rural areas, low level of supply of quality drinking water, lack of sewerage systems, lack and, in some villages, complete absence of cultural institutions, low accessibility of medical and educational services, as well as acute housing and employment issues. [3-4]

As a result, the working-age population migrates to industrial centers, which in turn leads to a decline in the birth rate and ageing of the village age structure [5].

Besides, shrinking of the rural population in result of migration is caused by a change in the category of settlements, i.e. conversion of urban to rural (or rural to urban) settlements by decision of the authorities.

\section{Results}

However, due to the increase in the number of people arriving in rural areas, this loss has slowed down since 2015. Figure 1 shows that the number of working-age population in rural areas has been steadily decreasing in recent years. All these issues can lead to the loss of public control over large areas and, as a result, to the loss of territorial integrity of our country.

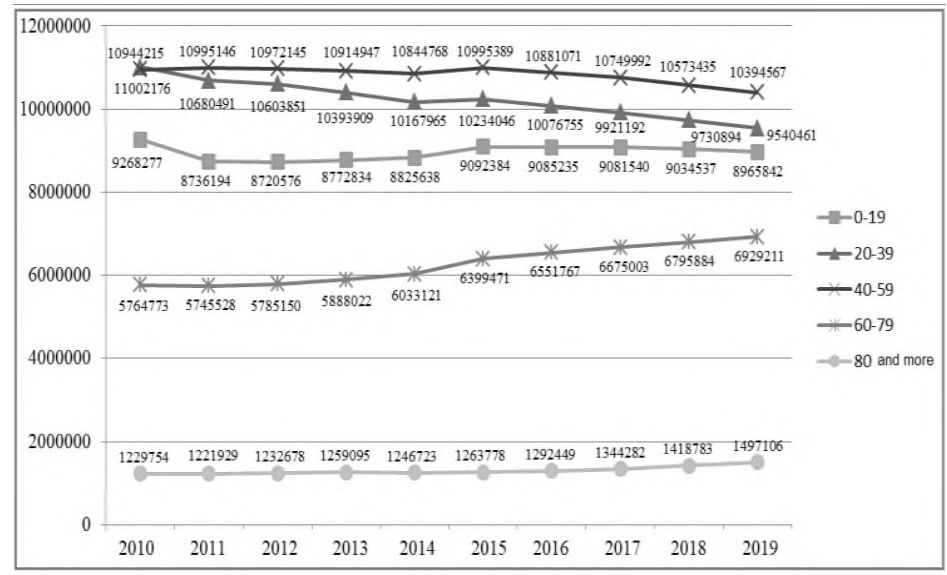

Fig. 1 Changes in rural population of different age groups by year

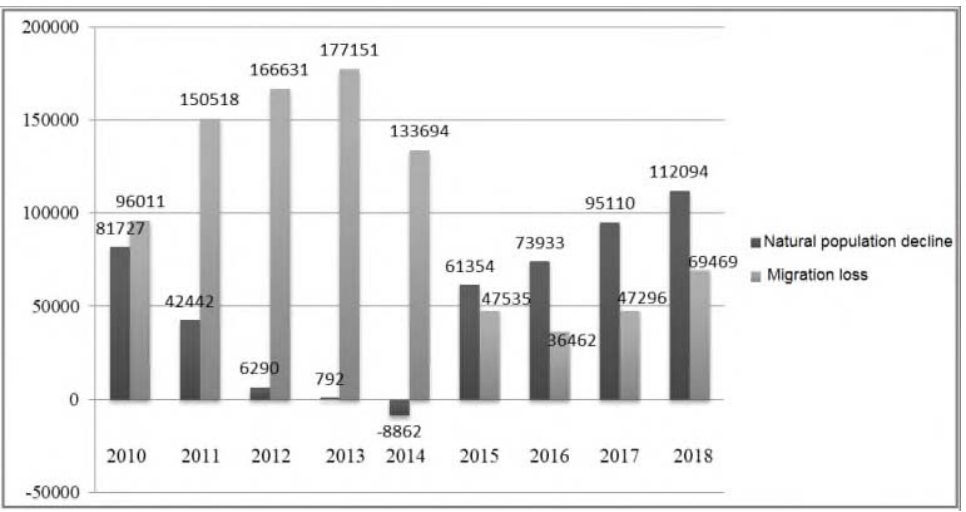

Fig. 2. Analysis of rural population decrease, people 
The social and economic development of these areas is worsening due to all a.m. factors. That, in turn, affects the performance of many national economic functions in rural areas which include as follows [6-7]:

- Production function: providing jobs and products to the population;

- Socio-demographic: reproduction of the population and improvement of their life quality;

- Cultural: creation and preservation of spiritual values, traditions, ceremonies, natural and artificial objects of cultural value and rural museums;

- Environmental protection: creation and preservation of natural monuments represented by unique, valuable natural complexes in terms of ecology, science and culture;

- Recreational: creating conditions and providing services for recreation, restoring and maintaining the moral and physical health of the population;

- Spatial communication: providing the country's economy with land as a spatial basis for engineering communications;

- Social control of the territory: support of state and local authorities by the rural population in ensuring order and security [8].

All these important functions cannot be performed by themselves but require a basis that would ensure the synergy of ecology, economy and society, through the interrelation of environmental processes, agricultural production and living environment of the rural population. This is the land and property complex of rural areas that acts as such a basis $[9,10]$.

\section{Discussion}

The development of rural areas, which are currently in crisis, can be understood as the implementation of federal programs for the sustainable development of rural areas, which are aimed at eliminating this crisis situation. The implementation of these programs in our country dates back to 2003 [11].

We need to create favorable conditions in rural areas to increase the number of agroproduction enterprises; provide young specialists and young families with housing; increase social development in rural areas by increasing the number of health, education, culture, sports and recreation facilities and providing modern equipment to existing facilities; organize the construction and reconstruction of roads within and between rural settlements; carry out gasification and water supply in rural settlements; develop a network of communication and telecommunications facilities; organize training and retraining for managerial staff in agricultural production, all these with a view to creating up-to-date rural settlements[12].

To sum up, we can say that sustainable development represents the development that meets the needs of the present without compromising the ability of future generations to meet their needs [13].

Since 2003, many programs have been implemented in Russia at various governmental levels.

There are also various regional or territorial programs aimed at improving the lives of rural settlements in a particular area.

The program passports describe their main objectives, tasks, principles and guidelines. Having read them, we can say that in many ways they are similar to each other.

Therefore, all these programs are aimed at:

- creating favorable socio-economic conditions for the village to perform its functions and improve the quality and standard of living of the population;

- increasing of the rural population and its life expectancy;

- reproducing and improving the efficiency of land and other resources used in agriculture, as well as greening production; 
- development of peasant (farm) households to increase production and sales of agricultural products, as well as increasing the number of family livestock farms based on peasant (farm) households;

- economic and territorial accessibility of social services and social facilities for all groups of rural population;

- environmental protection and rational use of natural resources;

- protection and enhancement of cultural values of the village [14].

These sustainable development programs are financed from the federal budget, budgets of the constituent entities of the Russian Federation and extra-budgetary sources. All these programs have been completed, discontinued, continued, and dissolved in each other.

An analysis of the results of the programs aimed at radically improving the social and economic condition of rural areas leads to the conclusion that, although the results show good indicators, they have not brought about expected changes, as all this has taken place over a fairly long period of time and the demographic situation in rural areas has not improved recently. As a result, the provision of basic social benefits to the rural population remains extremely low to date.

Having analyzed the results of the programs, we can identify the main factors that slow down the development of rural areas (see Fig. 3):

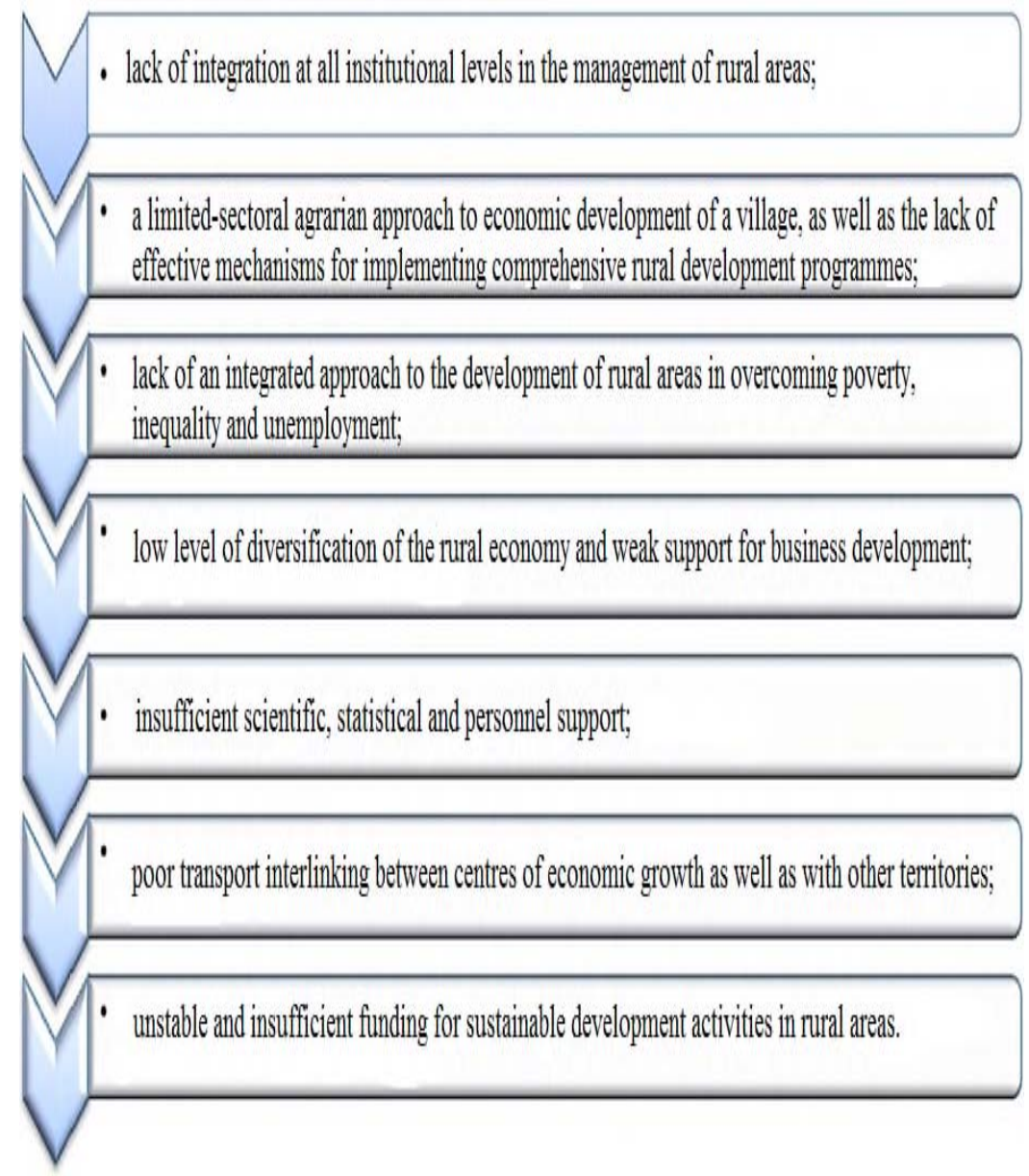

Fig. 3. Main factors hindering development of rural areas 
Therefore, the following solutions are offered to solve the problems that have arisen:

- creation of a department with full authority to make decisions in the area of land management, i.e. the creation of a state land service throughout Russia [];

- creation of a unified regulatory framework for sustainable development of rural areas;

- stable financial support for sustainable development of rural areas;

- improving the organizational and management mechanism for rural development;

- information and consulting support.

Thus, the measures undertaken to date and the results achieved are clearly insufficient to ensure a steady improvement in the quality and standard of living of the rural population. However, we still want to believe that all these efforts have not been made in vain and that life in rural areas will soon be much better.

\section{Conclusions}

Summing up, it may be noted that nowadays the main organizational and economic mechanism aimed at solving the tasks of comprehensive development of rural areas is federal targeted programs. Achieving sustainable development goals in rural areas is impossible without improving their demographic situation and, as a result, the labor resource base for the agricultural economy. It's fair to say that population dynamics is an indicator of sustainable development of rural areas in Russia.

Creating conditions for the sustainable development of rural areas is one of the most important strategic goals of the government policy, which ensures the effective use of the existing potential of the country's economy [15] .

When carrying out sustainable development measures in rural areas, it is necessary to take into account not only the human but also the ethnic characteristics of the rural population of our country, their natural, climatic and economic conditions that have arisen due to the spatial and territorial specifics. This should be based on the specifics of natural, climatic and economic conditions of the country's territories. As the basis for the economic and social well-being of our society, the sustainable development of rural areas must therefore become a priority for our state.

\section{References}

1. Immovable Property Cadastre, Cadastral activity in Russia: Experience of the present and prospects of the future, The 6th All-Russian Congress of Cadastral Engineers (SRO «Cadastral Engineers», Moscow, 2017)

2. M. Ogryzek, R. Wisniewski, T. Kauko, Real Estate Management and Valuation 26(3) (2018) https://doi.org/10.2478/remav-2018-0022

3. N. Ovchinnikova, D. Burdova, M. Garanova, E3S Web of Conferences 91 (2019) https://doi.org/10.1051/e3sconf/20199108023

4. T.S. Wilson, B.M. Sleeter, R.R. Sleeter, C.E. Soulard, Land 3(2) (2014) https://doi.org/10.3390/land3020362

5. J. Wójcik-Leńa, K. Sobolewska Mikulska, N. Sajnóg, P. Leń, Land Use Policy, 78 (2018) https://doi.org/10.1016/j.landusepol.2018.06.044

6. W. Han, X. Zhang, X. Zheng, Land Use Policy 92 (2020) https://doi.org/10.1016/j.landusepol.2019.104432

7. N.G. Ovchinnikova, MATEC Web of Conferences 10 .1051/matecconf/201710601004

8. N.G. Ovchinnikova, Terra economicus 7(2), 41-44 (2009) 
9. V.A. Chudovska, Balanced Nature Using, Institute of agroecology and environmental management, 7(4) (2016)

10. S. Lai, F. Leone, C. Zoppi, Sustainability 9(12) (2017) https://doi.org/10.3390/su9122174

11. S.G. Sheina,.A. Khamavova, Procedia Engineering $150 \quad$ (2016) https://doi.org/10.1016/j.proeng.2016.07.198

12. O. Mertz, C. F. Mertens, World Development $98 \quad$ (2017) https://doi.org/10.1016/j.worlddev.2017.05.002

13. M. Lengoiboni, C. Richter, Jaap Zevenbergen, Land Use Policy 85 (2019) https://doi.org/10.1016/j.landusepol.2019.03.023

14. B. Gilbey, J. Davies, G. Metternicht, C. Magero, Environmental Science \& Policy 100 (2019) https://doi.org/10.1016/j.envsci.2019.04.007

15. D. Smiraglia, T. Ceccarelli, S. Bajocco, L. Salvati, L. Perini, Environmental Research 147 (2016) https://doi.org/10.1016/j.envres.2015.11.030 